\title{
Phyto-oestrogen intake and implications for breast cancer therapy
}

\author{
S. Ramnarine ${ }^{1}$, H. Hinkley ${ }^{2}$ and M. Ritchie ${ }^{3}$ \\ ${ }^{1}$ University of Edinburgh, Edinburgh, UK, ${ }^{2}$ British College of Osteopathic Medicine, London, UK and \\ ${ }^{3}$ Napier University, Edinburgh, UK
}

Breast cancer is the most common malignancy among women and is the second leading cause of death ${ }^{(1)}$. Evidence suggests that a diet rich in phyto-oestrogens (PE) and vegetables is associated with a reduced risk of breast cancer ${ }^{(2)}$. The aim of the present study was to evaluate the role of PE in breast cancer therapy by initially assessing intake in a group of volunteers consuming a vegan diet (associated with a lower risk of cancer) and by conducting a literature review.

A newly-developed FFQ designed by the British College of Osteopathic Medicine was used to assess PE (total genistein and daidzein) intake in a group of vegan men and women $\left(n\right.$ 80). Mean intake was $33.4 \mathrm{mg} / \mathrm{d}^{(3)}$. Assessment of PE intake has useful implications in breast cancer research. Variations in the incidence of breast cancer in Eastern countries, e.g. in Japan where the incidence is one-third of that of Western countries ${ }^{(4)}$, may result from higher PE intakes. The average PE intake of Eastern populations ( $\left.30 \mathrm{mg} / \mathrm{d}\right)$ is much higher than that of Western populations $(\leq 10 \mathrm{mg} / \mathrm{d})^{(3)}$. PE may exert a 'protective role against breast cancer' ${ }^{\text {'(5) }}$. Using the FFQ to measure PE (tofu) intake in Asian-American women, it has been found that a higher tofu intake is associated with a significant decrease in breast cancer risk among premenopausal women $\left(15 \%\right.$ reduction in risk if consumed at least once weekly) ${ }^{(3)}$. There is evidence that increased $\mathrm{PE}$ consumption in a vegetarian diet is associated with a reduced incidence of breast cancer, validating the use of this new FFQ ${ }^{(2,6)}$.

Analysis and review of epidemiological, rodent and human studies revealed a potential role for PE in breast cancer therapy where exposure to $\mathrm{PE}$ is associated with alteration of oestrogen metabolism in a manner that may help reduce the ability of tumours to grow $^{(7-10)}$. Overall interpretation of results was complicated by methodological limitations (small sample size, selection and recall biases). Based on inconsistencies in evidence, it is apparent that the use of PE is still in its infancy, justifying a need for further research. To improve the integrity of the results a few guidelines should be implemented. First, there should be standardization in methodology, e.g. in the preparation of PE extracts. Stratification of PE levels is also necessary for meaningful comparison of 'low' and 'high' intakes between populations. Additionally, larger sample sizes in studies will assist in validating results. The mechanisms of action require further investigation in order to understand the interaction with current breast cancer therapies, as the evidence relating to the use of PE and Tamoxifen is conflicting ${ }^{(11)}$. Last, safety issues such as the long-term effects of PE warrant inspection. In the future the chemopreventative role of PE in breast cancer therapy should be developed in line with advances in genetic and molecular epidemiology of carcinogenesis' $^{,(12)}$.

1. National Breast Cancer Foundation Inc. (2007) What is breast cancer? http://www.nationalbreastcancer.org/About-Breast-Cancer/What-Is-BreastCancer/

2. Aldecreutz H (1984) Gastroenterology 86, 761-764.

3. Ritchie M, Ramnarine S, Wong W et al. (2008) Asssessment of Phyto-oestrogens intake in vegans using a newly developed food frequency questionnaire. Proceedings of the 5th International Soy and Health Conference Ghent, 2008.

4. Rice S \& Whitehead SA (2006) Endocr Relat Cancer 13, 995-1015.

5. Keinan-Boker L, van Der Schouw YT, Grobbee DE et al. (2004) Am J Clin Nutr 79, 282-288.

6. Wu AH, Ziegler RG, Horn-Ross PL et al. (1996) Cancer Epidemiol Biomarkers Prev 5, 901-906.

7. Wu AH and Pike MC (1995) Am J Clin Nutr 62, 151-153.

8. Granata OM, Traina A, Ramirez S et al. (2009) Ann N Y Acad Sci 1155, 232-236.

9. Cabanes A, Wang M, Olivo S et al. (2004) Carcinogenesis 25, 741-748.

10. Richter DU, Mylonas I, Toth B et al. (2009) Gynecol Endocrinol 25, 32-38.

11. Duffy C, Perez K \& Partridge A (2007) Cancer J Clin 57, 260-277.

12. Surh Y (2003) Nat Rev 3, 768-780. 